\title{
Grónica Parlamentaria
}

\section{El alcance del denominado "veto presupuestario" a la tramitación de las proposiciones de Ley}

La presentación, durante el mes de julio, de dos Proposiciones de ley generó un interesante debate acerca de los límites y posibilidades que tiene el Ejecutivo para impedir su tramitación al objeto de evitar la alteración del equilibrio presupuestario. En concreto, y por mencionarlas por el orden cronológico en el que se registraron, tales iniciativas legislativas fueron promovidas por el grupo parlamentario Podemos Andalucía (Proposición de Ley de Cuentas Claras y Abiertas para la Administración Pública Andaluza) y por el grupo parlamentario Popular Andaluz (Proposición de Ley relativa a Medidas Tributarias en el Impuesto sobre sucesiones y donaciones en Andalucía). Naturalmente, no es el objetivo de las siguientes páginas abordar el contenido de estas iniciativas, ni siquiera dar cuenta de sus líneas generales, lo que nos exime de avanzar más al respecto. Tan sólo nos interesa a los efectos de este trabajo mencionar un solo precepto de cada una de ellas. Por lo que hace a la Proposición del grupo parlamentario Podemos Andalucía, el apartado 1 de su disposición final: "La presente Ley entrará en vigor el 1 de noviembre de 2016". Y en lo tocante a la Proposición del grupo parlamentario Popular Andaluz, también su disposición final: "La presente Ley entrará en vigor a partir del 1 de enero de 2016". Esto es, lo único que conviene ahora destacar de ambas Proposiciones es que su entrada en vigor quedaría diferida al siguiente ejercicio presupuestario.

En la medida en que el Presupuesto puede considerarse la plasmación económico-financiera de la acción política diseñada por el Gobierno ${ }^{1}$, encuentra justificación que el ordenamiento le reconozca alguna capacidad para obstaculizar la aprobación de medidas legislativas que entrañen una alteración de sus previsiones de ingresos y gastos. Capacidad obstructiva que, como sucede en Francia, puede llegar incluso a la facultad de vetar este tipo de iniciativas; modelo por el que se inclinó el constituyente español. Así, tras reconocer la potestad genéri-

${ }^{1}$ Ya en la STC 27/1981 se definió como el "vehículo de dirección y orientación de la política económica que corresponde al Gobierno" (FJ 2º y así sigue recordándose de forma recurrente en la jurisprudencia constitucional. 
ca de las Cortes para enmendar el proyecto de Ley de presupuestos (art. 134.1 $\mathrm{CE})^{2}$, la Constitución consagra en términos inequívocos la referida prerrogativa gubernamental: "Toda proposición o enmienda que suponga aumento de los créditos o disminución de los ingresos presupuestarios requerirá la conformidad del Gobierno para su tramitación" (art. 134.6 CE).

Por lo demás, la incorporación de este veto presupuestario, lejos de entrañar un elemento disonante en nuestro sistema parlamentario, se inserta como un elemento más configurador de nuestro modelo de "parlamentarismo racionalizado". Así lo ha entendido, al menos, el Tribunal Constitucional en la STC 223/2006:

"La ejecución de un presupuesto en curso supone la verificación de dos confianzas: de un lado la obtenida por el Gobierno con la investidura de su Presidente; de otro la concedida específicamente por la Cámara a su programa anual de política económica. Así como la primera sólo se pierde en los casos expresamente establecidos (con el éxito de una moción de censura o el fracaso de una cuestión de confianza), la segunda se conserva a lo largo del período de vigencia natural (o prorrogada) del presupuesto, de suerte que el Gobierno puede pretender legítimamente que las previsiones económicas en él contenidas se observen rigurosamente en el curso de su ejecución. Puede pretender, en definitiva, que sólo sea relevante la oposición a su programa de gobierno traducida en una retirada formal de la confianza obtenida con la investidura y que, constante esa confianza, no se dificulte la ejecución del programa del Gobierno haciéndolo impracticable con la desnaturalización del programa económico sobre el que se asienta. Éste es el fundamento de la facultad que se le reconoce al Ejecutivo para oponerse a la tramitación de iniciativas legislativas que puedan desvirtuar el instrumento económico de su acción de gobierno." (FJ $6^{\circ}$ )

Pues bien, ésta es igualmente la fórmula asumida por el Estatuto andaluz, cuyo artículo 190.1 viene a ser una refundición casi literal de lo establecido para el Estado en los apartados primero y sexto del art. $134 \mathrm{CE}$ :

"Corresponde al Consejo de Gobierno la elaboración y ejecución del presupuesto de la Comunidad Autónoma y al Parlamento su examen, enmienda, aprobación y control. Toda proposición o enmienda que suponga un aumento de los créditos o disminución de los ingresos presupuestarios requerirá la conformidad del Consejo de Gobierno para su tramitación”.

2 "Corresponde al Gobierno la elaboración de los Presupuestos Generales del Estado y a las Cortes Generales su examen, enmienda y aprobación". 
En línea con lo sostenido en relación con los preceptos constitucionales reguladores de los Presupuestos Generales del Estado ${ }^{3}$, cabe interpretar este art. 190.1 del Estatuto en el sentido de que el veto gubernamental no se proyecta, limitándola, sobre la facultad de enmienda del Parlamento en relación con el proyecto de Ley de Presupuestos, sino que el mismo únicamente resulta operativo una vez que el Presupuesto ha sido aprobado ${ }^{4}$. Y el Tribunal Constitucional ya ha tenido ocasión de subrayar ese mayor margen de maniobra de enmienda de que dispone el Parlamento durante la tramitación de la Ley de Presupuestos: "Las discrepancias con las prioridades presupuestarias del ejecutivo pueden expresarse $[\ldots]$ mediante la potestad de enmienda y aprobación de los presupuestos y, en último caso, con el uso de los instrumentos de exigencia de responsabilidad previstos estatutariamente. Pero es claro que, una vez aprobados, y durante su ejecución (que corresponde en exclusiva al Gobierno - controlada, eso sí, por la Asamblea), no pueden, sin el consentimiento del Ejecutivo, plantearse iniciativas que alteren el equilibrio de los presupuestos" (STC 223/2006, FJ 6 ${ }^{\circ}$ ).

Y el Reglamento del Parlamento de Andalucía se encarga de regular con detalle el procedimiento de aplicación de dicho veto presupuestario. Una vez ejercitada la iniciativa legislativa, el artículo 124.2 RP establece que "la Mesa del Parlamento ordenará la publicación de la proposición de ley y su remisión al Consejo de Gobierno para que manifieste su criterio respecto a la toma en consideración, así como su conformidad o no a la tramitación si implicara aumento de los créditos o disminución de los ingresos presupuestarios". Y "transcurridos quince días sin que el Consejo de Gobierno hubiera negado expresa y motivadamente su conformidad a la tramitación, la proposición de ley quedará en condiciones de ser incluida en el orden del día del Pleno para la toma en consideración” (art. 124.3 RP).

Ahora bien, el Reglamento no se limita a establecer un procedimiento a través del cual el Ejecutivo ejercita un derecho de veto en principio incondicionado, sino que fija además una regla que restringe sustancialmente el margen de libre apreciación del Gobierno en beneficio del Parlamento. Así es; el art. 124.4 RP

${ }^{3}$ Luis María Cazorla Prieto: "Comentario al artículo 134.6", en Fernando Garrido Falla (coord.): Comentarios a la Constitución, $3^{\text {a }}$ edición, Civitas, Madrid, 2001, págs. 2320-2321.

${ }^{4}$ Ello no quiere decir que la capacidad de enmienda sea idéntica a la que se ostenta con carácter general, toda vez que, siguiendo asimismo el modelo de las Cortes, dicha capacidad genérica se ha visto matizada a nivel reglamentario: "Las enmiendas al proyecto de Ley de Presupuestos de la Comunidad Autónoma de Andalucía que supongan aumento de crédito en algún concepto únicamente podrán ser admitidas a trámite si, además de cumplir los requisitos generales, proponen una baja de igual cuantía en la misma sección" (art. 131.2 RP). 
contempla la eventualidad de que no exista "coincidencia de interpretación entre el Consejo de Gobierno y la Mesa del Parlamento respecto a si una proposición de ley, de aprobarse, supone o no aumento de los créditos o disminución de los ingresos del presupuesto en vigor"; y la controversia se resuelve atribuyendo la capacidad decisoria al Pleno.

Ha de advertirse, sin embargo, que la virtualidad real de este art. 124.4 RP debe ponderarse a la luz de la STC 223/2006, que resolvió sobre la constitucionalidad de un precepto semejante del Reglamento del Parlamento de Extremadura por contradecir lo dispuesto en el art. 60 b) del Estatuto extremeño (redacción de 1999), que establecía el veto presupuestario del Ejecutivo en términos prácticamente idénticos a los utilizados en el art. 190.1 de nuestro Estatuto. Pues bien, a juicio del Tribunal Constitucional, la disposición reglamentaria conducía "pura y simplemente a privar al Consejo de Gobierno de la Junta de Extremadura de la facultad que tiene reconocida en el art. 60 b) EAE, facultad que viene justificada como consecuencia de la asunción de los principios básicos del llamado ‘parlamentarismo racionalizado' por parte tanto del Texto constitucional español como de los Estatutos de las diferentes Comunidades Autónomas" (STC 223/2006, FJ 6 ${ }^{\circ}$. En efecto, proseguiría el Tribunal, "Mesa y Pleno se erigen en jueces de si concurren o no las circunstancias que permiten al Consejo de Gobierno de la Junta de Extremadura oponerse a la tramitación de iniciativas normativas que alteren el equilibrio presupuestario", lo que supone modificar la regla fijada en el Estatuto, según la cual "corresponde al Consejo de Gobierno de la Junta de Extremadura la conformidad para tramitar toda proposición o enmienda que suponga aumento de los créditos o disminución de los ingresos presupuestarios, sin prever los límites a dicha potestad" derivados del Reglamento parlamentario. Por consiguiente, la disposición reglamentaria distorsiona "el sistema de relaciones entre la Junta y la Asamblea previsto estatutariamente", el cual, en relación con los compromisos económicos asumidos mediante la aprobación por el Parlamento del presupuesto, parte de la premisa de que "solamente se podrán alterar dichos compromisos con el consentimiento del Ejecutivo autonómico, quedando facultado éste, con toda libertad, para oponerse a las iniciativas que pretendan modificarlos, y sin que puedan los órganos parlamentarios emitir un juicio sobre el carácter de manifiestamente infundada o no de tal oposición". Así pues, insistiría al respecto el Tribunal en el aludido FJ 6 " "al introducirse una norma que los habilita para realizar dicha tarea se está claramente trasladando la potestad de decidir del Gobierno a la Asamblea de la Comunidad Autónoma, alterando así el equilibrio de poderes previsto en el Estatuto de Autonomía, equilibrio de poderes diseñado en línea con las interpretaciones más recientes del régimen parlamentario (a las que responde, sin duda, el diseño de la forma de gobierno en la Comunidad Autónoma de Extremadura), en las que se ha pretendido reforzar la posición de los ejecutivos y, singularmente, de sus pre- 
sidentes, en aras de dotar a todo el sistema de una mayor estabilidad y mejorar su funcionamiento" 5 .

En resumidas cuentas, el art. 124.4 del Reglamento del Parlamento de Andalucía ha de "releerse" de conformidad con esta jurisprudencia constitucional, según la cual el veto presupuestario, en la medida en que el art. 190.1 del Estatuto lo atribuye al Ejecutivo en términos incondicionados, no puede quedar al albur de la decisión del Parlamento.

Una vez delimitado el marco normativo en el que se ha desenvuelto la controversia, procede ya volver a la narración del modo en que la misma se fue fraguando en sede parlamentaria. Transcurrido el plazo de quince días sin que el Consejo de Gobierno hubiera negado expresa y motivadamente su conformidad a la tramitación de las dos referidas Proposiciones de Ley, ambas quedaron en condiciones de ser incluidas "en el orden del día del Pleno para su toma en consideración", según lo previsto en el art. 124.3 RP. Y, sin embargo, a principios de agosto se presentaron sendos escritos en el Registro de la Cámara en donde constaban los acuerdos del Consejo de Gobierno en los que manifestaba su criterio contrario a la toma en consideración, así como su disconformidad con la tramitación de las repetidas Proposiciones. Por lo que hace a la presentada por el Grupo Podemos - y ciñéndonos al tema que nos interesa-, el Gobierno adujo en relación con la exigencia de depurar información por aplicación de la normativa de protección de datos que la Proposición "obvia la ingente cantidad de información que debería ser revisada, centrando todo su argumento en la facilidad de manejo del gestor de contenido que da soporte a los distintos portales de la Junta de Andalucía". Por el contrario, frente a esta argumentación del grupo parlamentario proponente, sostendría el Consejo de Gobierno: "Resulta evidente que el personal necesario para llevar a cabo esa tarea supone un coste económico, implicando por tanto un aumento de los créditos presupuestarios sin que exista pre-

${ }^{5}$ Y reforzaría aún más su argumentación en este mismo FJ 6: "El órgano facultado estatutariamente para decidir si se produce o no dicha alteración es el Gobierno, al que se le supone, en general, dotado de la confianza de la Cámara tras su obtención mediante los mecanismos de investidura; y al que ha de reconocerse, en particular tras la aprobación de los presupuestos, el apoyo necesario para poder desarrollar el programa económico anual expresado en aquéllos. Dentro del período de vigencia de un presupuesto siempre podrá la Asamblea, en caso de discrepancia grave, retirar la confianza parlamentaria al Gobierno utilizando al efecto los instrumentos de censura que están a su disposición. Lo que no es compatible con un 'sistema parlamentario racionalizado', como el previsto en el Estatuto de Autonomía de Extremadura, es pretender gobernar mediante decisiones parlamentarias puntuales que alteren los términos de la relación de confianza establecida entre Asamblea y Consejo de Gobierno en el campo presupuestario, que es donde se expresan con mayor claridad las prioridades de la acción política en general y de la gubernativa en particular”. 
visión de dotación alguna para tal fin”6. Respecto de la Proposición promovida por el Grupo Popular, sería la disminución de los ingresos la razón esgrimida para oponerse a su tramitación: "La Proposición de Ley va dirigida a la adaptación de una serie de medidas tributarias que afectan al Impuesto sobre Sucesiones y Donaciones y que llevan de facto a la desaparición del Impuesto. [...] En cuanto a las medidas concretas que se proponen, cabe efectuar distintas consideraciones. Por una parte, las reducciones incluidas en los artículos 17 bis, 19 y 20 del Texto Refundido sobre tributos cedidos, en la redacción dada por la presente Proposición de ley, llevarían a la supresión de la tributación de la práctica totalidad de los sujetos pasivos del Impuesto en su modalidad de 'Sucesiones'. Por otra parte, la medida propuesta sobre bonificaciones de la cuota en el nuevo artículo 22 septies del Texto Refundido supondría de facto la eliminación progresiva del Impuesto en la Comunidad Autónoma de Andalucía. La supresión del Impuesto conllevaría una disminución de ingresos presupuestarios por el mismo, hasta hacerlos inexistentes" $"$.

La cuestión central que planteaban estos acuerdos del Consejo de Gobierno era determinar si el veto presupuestario del Ejecutivo puede utilizarse cuando el Presupuesto en vigor no se ve afectado por las Proposiciones de Ley en cuestión, toda vez que - como apuntamos al comienzo de esta crónica- ambas preveían su entrada en vigor para el ejercicio presupuestario del año 2016. En línea de principio, el propio Reglamento del Parlamento parece apuntar a que esa facultad gubernamental se ciñe al presupuesto del año en curso, pues al presupuesto en vigor se refiere expresamente el apartado cuarto de su artículo $124^{8}$.

Y, realmente, lo dispuesto en el art. 124.4 RP probablemente no valga más que como argumento ad abundantiam, pues la aplicación del veto presupuestario únicamente al presupuesto en curso y no a los futuros presupuestos podía considerarse asumida ya implícitamente por las anteriores disposiciones. De hecho, ésta es la posición que ha terminado configurándose como absolutamente preponderante en la doctrina sobre el alcance del veto presupuestario, hasta el punto de que venía aceptándose en los últimos años con naturalidad. En este sentido, no ha de extrañar que la parte recurrente en el proceso que dio origen a la STC

${ }^{6}$ BOPA núm. 87, X Legislatura, de 9 de octubre de 2015, pág. 46.

${ }^{7}$ BOPA núm. 87, X Legislatura, de 9 de octubre de 2015, págs. 48- 49.

8"Si no existiese coincidencia de interpretación entre el Consejo de Gobierno y la Mesa del Parlamento respecto a si una proposición de ley, de aprobarse, supone o no aumento de los créditos o disminución de los ingresos del presupuesto en vigor, el Pleno decidirá tras un debate en el que intervendrán los diversos Grupos parlamentarios en un único turno de diez minutos". 
223/2006 ni siquiera se plantease como hipótesis de trabajo otra posible interpretación de la facultad gubernamental prevista en el Estatuto: "Otra novedad introducida por la reforma, consistente en que todas estas previsiones sólo se refieren al ejercicio presupuestario en curso, no es objeto de discusión por los ahora recurrentes, quienes entienden que únicamente se ha hecho explícita una previsión implícitamente contenida ya en el propio Estatuto de Autonomía de Extremadura" (FJ $\left.4^{\circ}\right)$.

De acuerdo, pues, con la posición doctrinal mayoritaria, el veto presupuestario se extiende únicamente al presupuesto vigente al tiempo del examen de la enmienda o proposición en cuestión. Y ésta es una conclusión a la que se llega igualmente tras analizar el debate en sede constituyente ${ }^{9}$. En la redacción que dio el Informe de la Ponencia del Congreso a la norma que se convertiría en el actual art. 134.6 CE, se mencionaba el aumento de gasto y la disminución de ingresos en términos genéricos, sin precisar que se trataban de créditos e ingresos "presupuestarios"10. Esta adición se incorporaría en el Dictamen de la Comisión de Asuntos Constitucionales y Libertades Públicas ${ }^{11}$ a raíz de la siguiente intervención de Fraga Iribarne: "El señor De la Fuente en su enmienda número 35 trata del sutil equilibrio que se plantea siempre en estas cuestiones en todos los Derechos Parlamentarios para conseguir que el Gobierno tenga la iniciativa en materia presupuestaria y, al mismo tiempo, una responsabilidad de control del conjunto del gasto; pero, por otra parte, para que esta prioridad... no destruya la posibilidad de que por vía de proposición de ley se puedan proponer cosas razonables que en algún caso puedan implicar aumento de gastos, se establece un equilibrio, que es tradicional y viene básicamente del Derecho parlamentario británico, que es el de que las proposiciones o enmiendas que entrañen aumento de gastos o disminución de ingresos requieran la conformidad del Gobierno para su tramitación. Pero se entiende que esto debe ser dentro del mismo ejercicio, porque si no el cálculo de esas im-

\footnotetext{
${ }^{9}$ Para más detalles sobre el particular, véase Luis María Cazorla Prieto: "Comentario al artículo 134.6”, en Fernando Garrido Falla (coord.): Comentarios a la Constitución, $3^{\text {a }}$ edición, Civitas, Madrid, 2001, pág. 2323.

${ }^{10} \mathrm{El}$ entonces apartado quinto del art. 126 del Informe de la Ponencia del Congreso de los Diputados decía así: "Aprobados los Presupuestos Generales del Estado, únicamente el Gobierno podrá presentar proyectos de ley que impliquen aumento del gasto público o disminución de los ingresos, y toda proposición o enmienda que entrañe aumento de gasto o disminución de ingresos requerirá la conformidad del Gobierno para su tramitación".

${ }^{11} \mathrm{El}$ art. 128.5 del Dictamen de la Comisión pasó a tener la siguiente redacción: "Aprobados los Presupuestos Generales del Estado, el Gobierno podrá presentar proyectos que impliquen aumento de gasto o disminución de los ingresos correspondientes al mismo ejercicio presupuestario. Toda proposición o enmienda que aumento de los créditos o disminución de los ingresos presupuestarios requerirá la conformidad de Gobierno para su tramitación”.
} 
plicaciones podría llevar muy lejos y, por otra parte, lo que no puede tampoco el Gobierno es prejuzgar que en el próximo Presupuesto no se pueden incluir estos aumentos. Por tanto, se propone que, manteniéndose las limitaciones tradicionales indicadas, se puntualice que se refieren al mismo ejercicio presupuestario y que eso no puede servir como pretexto para que una proposición de ley que signifique aumento de gasto no sirviese para otros ejercicios, porque eso forma parte de la naturaleza de la legislación progresiva" (la cursiva es nuestra) ${ }^{12}$.

A la vista del proceso de conformación de la norma, no ha de extrañar que se fundamente en estos "precedentes parlamentarios" la tesis de que "aquellas iniciativas parlamentarias que no afecten al ejercicio presupuestario en curso, y sí a ejercicios futuros, no están sometidas a la necesidad de conformidad del Gobierno para su tramitación"; y, de hecho, conforme a este criterio se ha venido procediendo en la práctica parlamentaria del Congreso de los Diputados ${ }^{13}$.

Ciertamente, no exista ninguna base en el Estatuto andaluz que permita sostener una lectura diversa a la mantenida generalizadamente en la doctrina respecto de las Cortes Generales; puesto que, en la específica cuestión que nos ocupa, como sucede en general con la materia presupuestaria ${ }^{14}$, el Estatuto tiene una identidad sustancial con la regulación constitucional.

Éste es, sucintamente descrito, el escenario normativo en el que se desarrolló en la Mesa del Parlamento de Andalucía la controversia en torno a la aceptación de la oposición gubernamental a la tramitación de las tantas veces repetidas Proposiciones de Ley. Pues bien, en la sesión de la Mesa de 16 de septiembre, tras ser requerido el Letrado Mayor para que efectuase un informe oral -en el que se mostró proclive a la admisión a trámite de las mismas-, se produjo un empate al inclinarse tres miembros de la Mesa por la posición del Gobierno, otros tres en contra y contabilizarse una abstención. Bloqueada, así, la adopción de una decisión al respecto, la Mesa volvería a tratar el tema en sesión celebrada el 23 de septiembre, en la que se solicitó al Letrado Mayor un informe jurídico expreso sobre el particular. Y en dicho informe, fechado el 30 de septiembre, se ratificaría en su posición inicial. Según se reflejó en diversos medios de comunicación, la conclusión de que tanto la Proposición de Ley presentada por el Grupo Podemos como la impulsada por el Grupo Popular cumplían los requisitos para su admisión se fundamentaba expresamente en que am-

12 Diario de Sesiones del Congreso de los Diputados, núm. 87, sesión núm. 19, martes 13 de junio de 1978, pág. 3212.

${ }^{13}$ Luis María Cazorla Prieto, op cit, pág. 2325.

14 Miguel Azpitarte Sánchez, "Comentario al art. 190”, en Cruz Villalón/Medina Guerrero (drs.): Comentarios al Estatuto de Autonomía para Andalucía, vol. IV, Parlamento de Andalucía, Sevilla, 2012, pág. 2726. 
bas "difieren expresamente su entrada en vigor, y en consecuencia sus eventuales efectos presupuestarios, al 1 de noviembre de 2016 y al 1 de enero, respectivamente, sin que pueda considerarse afectado por tanto el presupuesto en curso". Por cuanto llevamos dicho hasta ahora, parece evidente que no puede sino suscribirse íntegramente la argumentación del Letrado Mayor.

Comoquiera que sea, lo cierto es que el debate generado en torno a la tramitación de tales Proposiciones ha servido, cuando menos, para avanzar en la interpretación de algún concepto utilizado en el Reglamento del Parlamento andaluz sobre cuyo alcance y significado se había escrito muy poco. Nos referimos a la noción de "antecedentes necesarios" que se utiliza en el art. 123: "Las proposiciones de ley se presentarán acompañadas de una exposición de motivos y de los antecedentes necesarios para pronunciarse sobre ellas". Nuevamente, nos hallamos frente a una disposición reglamentaria que se inspira en una norma relativa al Estado, a saber, el art. $88 \mathrm{CE}$, aunque en este caso se refiere a los proyectos de ley ${ }^{15}$ : "Los proyectos de ley serán aprobados en Consejo de Ministros, que los someterá al Congreso, acompañados de una exposición de motivos y de los antecedentes necesarios para pronunciarse sobre ellos".

Pero ¿qué son esos "antecedentes necesarios" a los que aluden las normas mencionadas? Lo cierto es que se trata de un concepto escasamente perfilado a nivel doctrinal; carencia a la que muy probablemente no haya sido ajena la circunstancia de que el precepto carezca de parangón en Derecho comparado ${ }^{16}$. Por lo demás, contadísimas han sido las ocasiones en que se ha planteado al Tribunal Constitucional algún interrogante al respecto, y cuando se ha pronunciado no lo ha hecho abiertamente sobre el alcance del concepto de "antecedentes necesarios", sino únicamente sobre las consecuencias del incumplimiento de esta exigencia. Más concretamente, ha apuntado que "la ausencia de un determinado antecedente sólo tendrá transcendencia si se hubiere privado a las Cámaras de un elemento de juicio necesario para su decisión" (STC 108/1986).

Pues bien, a la concreción de ese evanescente concepto apunta la Resolución de la Presidencia del Parlamento de Andalucía, de 30 de septiembre de $2015^{17}$. Como es sabido, es posible integrar el contenido de los Reglamentos parlamentarios

${ }^{15}$ Aunque debe dejarse constancia que el Reglamento del Parlamento andaluz extiende también la exigencia a los proyectos de ley (art. 109.1).

${ }^{16}$ Piedad García Escudero: "Comentario al art. 88 CE”, en Casas Baamonde/Rodríguez-Piñero (dirs.): Comentarios a la Constitución española, Wolters Kluwer, Madrid, 2008, pág. 1528.

${ }^{17}$ Boletín Oficial del Parlamento de Andalucía, núm. 82, X Legislatura, 2 de octubre de 2015, págs. 6-7. 
a través de normas supletorias o interpretativas tendentes a cubrir lagunas o a superar oscuridades que dificulten su comprensión, correspondiendo al Presidente de la Cámara el desempeño de esta tarea ${ }^{18}$. La Resolución parte, pues, de la constatación del hecho de que "ningún precepto de reglamento parlamentario ni de ninguna otra norma general aclara" el significado del concepto; lo que le lleva a considerar que nos hallamos "ante un requisito abierto, una simple cláusula de cierre con la que no parece pretenderse hacer alusión a ningún tipo concreto de documentación". Y, sin embargo, "es una obligación reglamentaria que la Mesa debe poder apreciar para entender cumplidos los requisitos requeridos a una iniciativa legislativa para su admisión a trámite". En definitiva, al objeto de facilitar esa tarea revisora de la Cámara, la Resolución viene a acotar la expresión "antecedentes necesarios" de los artículos 109.1 y 123 RP apuntando que "comprende al menos" la exposición de motivos y el "cálculo estimado del coste económico que supondría su aprobación”; cálculo para el que los "grupos parlamentarios podrán solicitar las informaciones que precisen de los servicios de la Cámara" (apartado primero). Importa en cualquier caso notar que, como refleja expresamente el encabezamiento de la Resolución, su incumplimiento no tiene por qué suponer "necesariamente la inadmisión a trámite de la iniciativa". Por lo demás, según establece la Disposición transitoria de la Resolución, la misma "será de aplicación a los proyectos y proposiciones de ley que a su entrada en vigor se encuentren pendientes de debate de totalidad o toma en consideración"19.

Tras este proceloso periplo seguido por las iniciativas legislativas que nos han venido ocupando, la Mesa del Parlamento de Andalucía, en sesión celebrada el 5 de octubre, pondría fin a la controversia poniendo de manifiesto su no coincidencia con la interpretación del Consejo de Gobierno de que las Proposiciones presentadas por Podemos y el grupo Popular implicaban, respectivamente, un aumento de los créditos y una disminución de los ingresos presupuestarios. Y en esa misma sesión de 5 de octubre, la Mesa acordó tramitar por el procedimiento de urgencia ambas Proposiciones, así como otorgar a los grupos parlamentarios proponentes un plazo de ocho días hábiles para aportar los "antecedentes necesarios" según lo establecido en el apartado primero de la recién citada Resolución de la Presidencia del Parlamento.

Manuel Medina Guerrero

18 Según establece el art. 29 del Reglamento del Parlamento andaluz: "Corresponde al Presidente o Presidenta del Parlamento las siguientes funciones: (...) $2^{\circ}$ Cumplir y hacer cumplir el Reglamento, interpretándolo en los casos de duda y supliéndolo en los de omisión. Cuando en el ejercicio de esta función supletoria se propusiera dictar una resolución de carácter general, deberá mediar el parecer favorable de la Mesa y de la Junta de Portavoces".

${ }^{19}$ La Resolución entró en vigor el día de su publicación en el BOPA, esto es, el día 2 de octubre. 